Check for updates

Cite this: RSC Adv., 2019, 9, 20149

\title{
Influence of L-arginine on performances of polyamide thin-film composite reverse osmosis membranes
}

\author{
Dandan Chen, Qiang Chen, Tianyu Liu, Jian Kang, (D) Ruizhang Xu, (D) * Ya Cao \\ and Ming Xiang
}

To prepare polyamide thin-film composite reverse osmosis (PA-TFC-RO) membranes with high performance, L-arginine (Arg) was used as an additive in $m$-phenylenediamine (MPD) aqueous solution. Arg with active amine groups can react with 1,3,5-benzenetricarboxylic chloride (TMC) to be incorporated into the polyamide selective layer during interfacial polymerization. X-ray photoelectron spectroscopy verified the successful introduction of Arg into the polyamide selective layer. Scanning electron microscopy, atomic force microscopy, contact angle and zeta potential measurements manifested that the polyamide selective layer was thinner, smoother, more hydrophilic and less negatively charged after the incorporation of Arg. The thinner and more hydrophilic polyamide selective layers favor the boosting of the permeability of the RO membrane by decreasing the hydraulic resistance to water permeation. Consequently, when the content of Arg was $0.5 \mathrm{wt} \%$, the water flux and salt rejection of the resulting membranes increased from the original $46.46 \mathrm{~L} \mathrm{~m}^{-2} \mathrm{~h}^{-1}$ and $96.34 \%$ to $54.13 \mathrm{~L} \mathrm{~m}^{-2} \mathrm{~h}^{-1}$ and $98.36 \%$. Besides, the modified membranes showed excellent fouling-resistance and easy-cleaning properties when tested by using bovine serum albumin (BSA) and dodecyltrimethyl ammonium bromide (DTAB) as model foulants.

Received 18th April 2019

Accepted 15th June 2019

DOI: 10.1039/c9ra02922b

rsc.li/rsc-advances optimizing the separation performance and fouling-resistant properties of RO membranes. ${ }^{13,14}$

Membrane fouling is a ubiquitous phenomenon in the process of water treatment due to the relatively hydrophobic and rough membrane surface. ${ }^{15,16}$ Feed pretreatment and periodic cleaning are frequently implemented, which are costly and unable to solve the fouling problem thoroughly. ${ }^{17}$ Hence, the development of anti-fouling RO membranes is a crux to deal with this issue. Currently, surface modification would be a promising method to alleviate membrane fouling by tailoring the surface properties of the PA selective layer such as hydrophilicity, charge property and roughness. ${ }^{18,19}$ Various hydrophilic materials such as zwitterionic polymers, PEG derivatives and modified nanoparticles have been widely utilized to enhance anti-fouling properties by enhancing the surface hydrophilicity or constructing smoother and less charged surface of the PA selective layer ${ }^{20-23}$ However, due to the unexpected permeation resistance caused by an additional layer, the water permeability of RO membranes would inevitably decline..$^{24}$

Currently, many researches dedicated to adjusting the chemical structure of the PA selective layer by affecting the interfacial polymerization, so as to fabricate RO membranes with excellent water permeability as well as superior antifouling properties. ${ }^{25,26}$ The overall salt rejection and water flux of RO membranes can be optimized by the type and concentration of monomer in aqueous or organic solution, monomer 
ratio and the diffusion rate of the monomers. ${ }^{27,28}$ For example, $\mathrm{Yu}$ et $a .^{29}$ replaced typical monomers with cyclohexane-1,3,5tricarbonyl chloride (HTC) and $m$-phenylenediamine-4-methyl (MMPD). The experimental result showed that membrane performances were improved due to the increase of crosslinking density and hydrophilicity of the PA selective layer. However, developing a new selective layer through synthesizing new monomers is a complicated fabrication procedure. Therefore, introducing additive into the MPD aqueous phase may be a potential candidate. For example, Zhou Yong et al. ${ }^{30}$ incorporated hydrophilic $m$-phenylenediamine-5-sulfonic acid (SMPD) into the aqueous phase to enhance the hydrophilicity of the PA selective layer. Besides, various hydrophilic polymers such as polyvinyl alcohol (PVA) and polyvinyl phenol (PVP) were added into the aqueous phase to improve the surface hydrophilicity and decrease the surface roughness of the PA selective layer, ${ }^{31,32}$ but the stereo-hindrance effect brought by bulk volume of polymer chain might produce adverse effects such as the pore defects or collapse. All the resulting membranes exhibited an enhanced performance, but the complex operation process and the sacrifice of salt rejection are still big challenges of optimizing membrane performance by regulating the structure of the PA selective layer.

Given the consideration above, it is necessary to adopt a new material with small volume and good hydrophilicity for fabricating RO membranes with both excellent separation and fouling resistant performances in a facile way. L-Arginine, known as a hydrophilic biomaterial with flexible main chain, contains rich hydrophilic groups such as a complex guanidine group, an $\alpha$-amino group and an $\alpha$-carboxylic acid group. ${ }^{33}$ The active amine groups in Arg can react with acyl chloride groups in TMC during interfacial polymerization (their reactivity can be proved from Fig. 2(a)), and thus the hydrophilic groups of Arg can be incorporated into the PA selective layer. Furthermore, it is accepted that introducing aliphatic monomers with flexible chain into the stiff aromatic PA could improve the mobility of polymer chains and thereby promote the transport of water molecules through membrane. ${ }^{34,35}$ Hence, the incorporation of Arg could increase the hydrophilicity of the PA selective layer and the mobility of the PA chain, which result in the improvement in water permeability of RO membranes by decreasing the hydraulic resistance of water molecule to pass through membranes while anti-fouling properties are also enhanced. In addition, due to the multiple amine groups in Arg, in one aspect, the reaction of Arg and TMC possibly form another crosslinked structure for maintaining high salt rejection; in another aspect, Arg exhibits as a cation that may improve the resistance of RO membranes to the positively charged foulants due to the electrostatic repulsion. ${ }^{36}$

Hence, in our research, hydrophilic monomer Arg was selected as an additive in the MPD aqueous solution and participated in the formation of the PA network structure. Furthermore, the role of Arg in the interfacial polymerization was also studied to understand the relationship between the structure and properties of the PA selective layer. Thus, different contents of Arg were added in the aqueous phase to prepare the PA selective layer. The resulting RO membranes were characterized and analyzed in terms of diffusion behavior of monomers, surface composition, morphology, thickness, roughness, hydrophilicity and charge. Also, the separation performance and the fouling resistance to bovine serum albumin (BSA) and dodecyltrimethyl ammonium bromide (DTAB) were also evaluated.

\section{Experimental}

\subsection{Materials and reagents}

The polysulfone (PSF, Udel® p-3500, $M_{\mathrm{n}}=22000 \mathrm{~g} \mathrm{~mol}^{-1}$ ) was purchased from Solvay Co. Ltd. 1,3,5-Benzenetricarboxylic chloride (TMC, purity > 98\%), m-phenylenediamine (MPD, purity $>99 \%$ ), L-arginine (Arg, purity > 99\%), bovine serum albumin (BSA, purity > 99\%) and dodecyltrimethyl ammonium bromide (DTAB, purity $>99 \%$ ) were purchased from Shanghai Aladdin Biochemical Technology Co. Ltd. Other reagents including $n$-hexane (purity > 97\%), $N, N$-dimethylformamide (DMF, purity $>99.5 \%$ ) and sodium chloride ( $\mathrm{NaCl}$, purity $>$ 99.5\%) were purchased from Chengdu Kelong Chemical Reagent Co. Ltd. Distilled water in all experiments was made by water distiller.

\subsection{Membrane preparation}

The polyamide RO membranes were composed by PSF support layer and PA selective layer.

The PSF support layer was prepared by way of non-solvent induced phase separation (NIPS), which was illustrated in our previous work. ${ }^{35}$ The PA selective layer was synthesized by interfacial polymerization reaction between the aqueous phase monomer and the organic phase monomer, and the chemical structure and formula of the PA selective layer are shown in Scheme 1 . The concentration of MPD in the aqueous phase and TMC in the organic phase are $2 \mathrm{wt} \%$ and $0.1 \mathrm{wt} \%$, respectively. Arg was dissolved in the MPD aqueous solution, with four concentrations of $0.1,0.3,0.5$ and $1.0 \mathrm{wt} \%$ (see Table 1). First, the aqueous solution was poured into the PSF support layer settled in a polyfluortetraethylene (PTEF) frame for $3 \mathrm{~min}$. Then, the excess solution was removed, and the membrane was dried by high-pressure nitrogen $\left(\mathrm{N}_{2}\right)$. Second, the saturated PSF support layer was immersed into TMC organic solution to proceed the interfacial polymerization for $30 \mathrm{~s}$. Then the creating membrane was rinsed by $n$-hexane to remove the unbonded TMC. Finally, all membranes were heat-treated at $45{ }^{\circ} \mathrm{C}$ for $10 \mathrm{~min}$ to stabilize their structure, and then stored in distilled water before measurements. In this study, no additives such as camphor sulfonic acid (CSA), sodium dodecyl sulfate (SDS) and triethylamine (TEA) were added. Moreover, the Arg additive membranes are noted by A-0.1, A-0.3, A-0.5 and A-1.0, and the non-additive membrane is indicated by $\mathrm{A}-0$.

\subsection{Diffusion behavior of MPD monomers}

The diffusion behavior of MPD toward the organic phase was characterized by measuring the absorbance variation of MPD in $n$-hexane over time, as described in the literature. ${ }^{37}$ First, we used microsyringe to add $1.0 \mathrm{~mL}$ aqueous solution (MPD: 


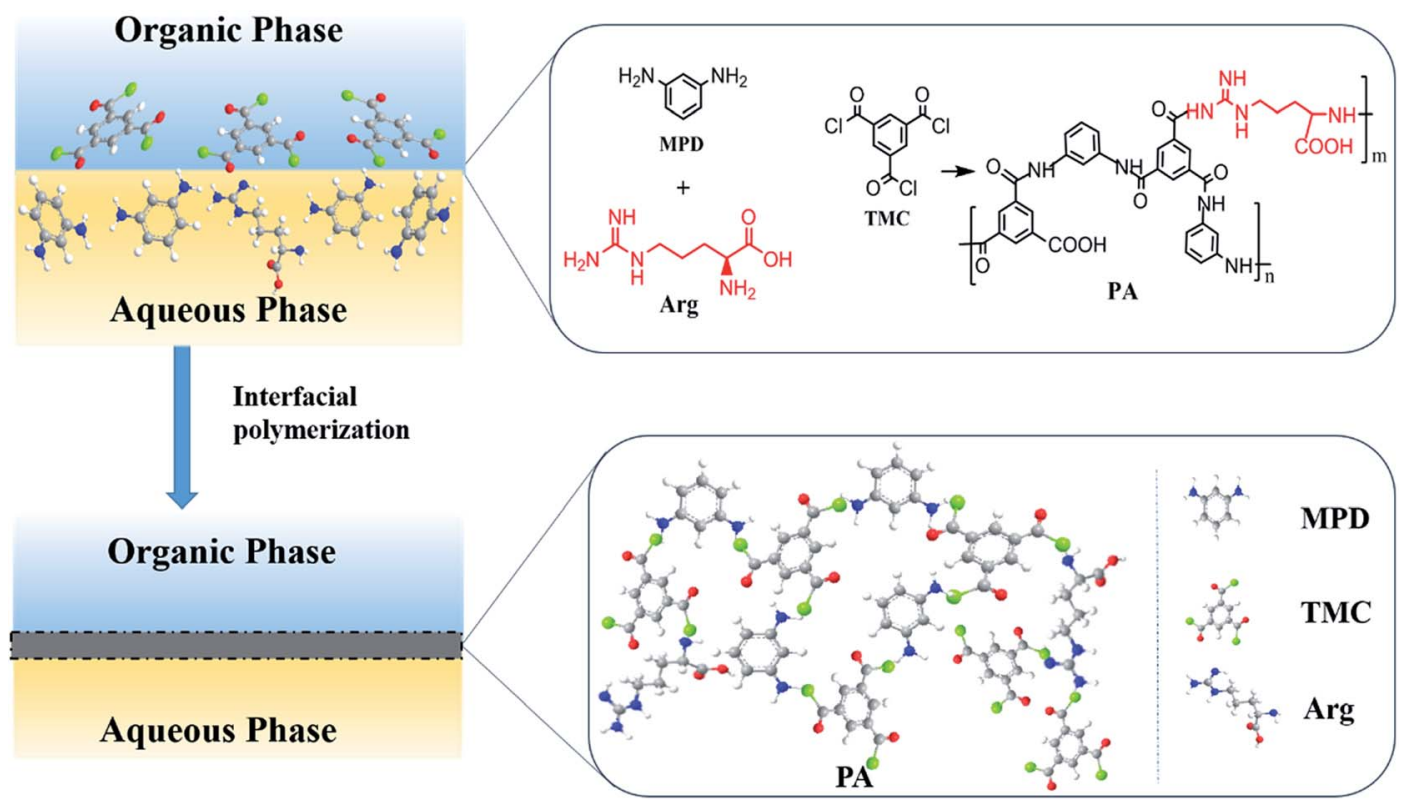

Scheme 1 The chemical structure and formula of PA selective layer from the interfacial polymerization of MPD, Arg and TMC.

$2.0 \mathrm{wt} \%$, Arg: 0, 0.1, 0.3, 0.5 and $1.0 \mathrm{wt} \%$, respectively) into the bottom of a quartz cuvette. Then, $2.0 \mathrm{~mL}$ pure $n$-hexane was carefully put into the cuvette by microsyringe, and the absorbance variation of MPD in $n$-hexane was simultaneously recorded by ultraviolet-visible (UV-vis) spectroscopy (TU-1900, PERSEE, China). Each diffusion process lasted for $10 \mathrm{~min}$. It is accepted that MPD has two typical absorption peaks in the ultraviolet region (240 $\mathrm{nm}$ and $289 \mathrm{~nm}$, respectively); whereas the characteristic peak of Arg locates in $216 \mathrm{~nm}$ (see from Fig. 1(a)). Hence, in this study, the peak in $289 \mathrm{~nm}$ was elected to present MPD concentration in hexane based on the BeerLambert law. ${ }^{38}$ The test was adopted to evaluate whether Arg affected the diffusion rate of MPD monomers from the aqueous phase to the organic phase. Each sample was measured three times to obtain the average value of absorbance.

\section{4. $\quad$ pH value of the aqueous phase solution}

The $\mathrm{pH}$ value of the aqueous phase solution has a significant influence on the formation of the PA skin layer by affecting the process of interfacial polymerization..$^{\mathbf{3 9 4 0}} \mathrm{pH}$ meter (PHS-3Cb,

Table 1 Compositions of the aqueous and organic solutions for the polyamide TFC membranes, and the $\mathrm{pH}$ values of the pure Arg aqueous solution and the mixture solutions of MPD and Arg

\begin{tabular}{|c|c|c|c|c|}
\hline \multirow[b]{2}{*}{ Samples } & \multicolumn{2}{|c|}{$\begin{array}{l}\text { Aqueous } \\
\text { solution (wt\%) }\end{array}$} & \multirow{2}{*}{$\begin{array}{l}\begin{array}{l}\text { Organic solution } \\
(\mathrm{wt} \%)\end{array} \\
\mathrm{TMC}\end{array}$} & \multirow{2}{*}{$\begin{array}{l}\mathrm{pH} \text { value of the } \\
\text { aqueous solution }\end{array}$} \\
\hline & MPD & $\operatorname{Arg}$ & & \\
\hline$A-0$ & 2.0 & 0 & 0.1 & $9.38 \pm 0.07$ \\
\hline $\mathrm{A}-0.1$ & 2.0 & 0.1 & 0.1 & $10.39 \pm 0.11$ \\
\hline A- 0.3 & 2.0 & 0.3 & 0.1 & $10.82 \pm 0.02$ \\
\hline A- 0.5 & 2.0 & 0.5 & 0.1 & $10.97 \pm 0.03$ \\
\hline A-1.0 & 2.0 & 1.0 & 0.1 & $11.10 \pm 0.06$ \\
\hline Arg & 0 & 2.0 & 0 & $11.37 \pm 0.02$ \\
\hline
\end{tabular}

Shanghai Yueping, China) was used to test the $\mathrm{pH}$ value of the aqueous phase solution with or without the existence of Arg.

\subsection{Membranes characterization}

All membrane samples were rinsed by distilled water and dried at $30{ }^{\circ} \mathrm{C}$ under vacuum for $12 \mathrm{~h}$ before characterization.

The chemical structure of the polyamide TFC membranes was analyzed by Fourier-transform infrared spectroscopy (FTIR) under the pattern of attenuated total reflectance (ATR) (Nicolet FTIR, Thermo Fisher Scientific, USA). Moreover, the penetration depth was approximate $600 \mathrm{~nm}$. Each spectrum was acquired at a resolution of $4 \mathrm{~cm}^{-1}$ for 32 scans in the region of $4000-$ $400 \mathrm{~cm}^{-1}$. X-ray photoelectron microscopy (XPS) (Axis Ultra DLD, Kratos Analytical, UK) was used to confirm the element composition of the membrane surface. The electron emission angle was installed at $45^{\circ}$ and the sampling depth is $<100 \AA$.

Scanning electron microscopy (SEM, FEI Inspect F, USA) was used to observe the surface morphology of the polyamide TFC membranes. The thickness of the skin layer was obtained by the cross-section images obtained by SEM (NOVA NANOSEM 450, FEI, USA). Membranes were fractured in liquid nitrogen for the SEM observation of the cross-section morphologies. Additionally, atomic force microscopy (AFM) (Asylum Research MFP-3D, Oxford Instruments, UK) was used to confirm the surface roughness. All membrane samples were set on a specimen holder and four $5 \times 5 \mu \mathrm{m}$ locations were inspected by tapping mode in air. The surface roughness was evaluated regarding peak-to-valley distance $\left(R_{\mathrm{p}-\mathrm{v}}\right)$, the root-mean-squared roughness $\left(R_{\mathrm{ms}}\right)$, the average roughness $\left(R_{\mathrm{avg}}\right)$ and relative surface area $(\Delta),{ }^{41,42}$ and these data were processed by Igor Pro $6.22 \mathrm{~A}$ software.

Goniometer (DSA30 drop shape analysis system, KRUSS) with sessile drop was employed to evaluate the static water contact angle. The value of the contact angle could judge the 
hydrophilicity of the membrane surface. A total drop of $3.0 \mu \mathrm{L}$ deionized water was placed on the dried membrane surface. All measurements were measured at least six times in a parallel line to obtain a reliable value.

SurPASS electrokinetic analyzer (Anton Paar, GmbH, Austria) was applied to measure the surface charge of the membrane. All membranes were immersed in $0.001 \mathrm{~mol} \mathrm{~L}^{-1} \mathrm{KCl}$ aqueous solutions at $25.0{ }^{\circ} \mathrm{C}$ in the $\mathrm{pH}$ range of 3.0 to 10.0 . The surface zeta potential was calculated from the measured streaming potentials based on the Helmholtz-Smoluchowski equation. ${ }^{43}$ All test data were obtained by three measurements of each membrane.

\subsection{Separation performance measurement}

The pure water flux and rejection of the RO membrane was evaluated by a laboratory-scale cross-flow filtration instrument (FlowMem-0021-HP, Xiamen Filter \& Membrane Technology Co., Ltd, China). Membranes with effective surface area $60 \mathrm{~cm}^{2}$ were put into the cell for filtration. Before the measurement permeation of the flux and salt rejection, each membrane was pressed with distilled water to stabilize the filtration system. The permeation flux and salt rejection were tested in $2000 \mathrm{ppm}$ $\mathrm{NaCl}$ aqueous solution under the cross-flow velocity of about 7 $\mathrm{L} \min ^{-1}$ and 1.6 MPa transmembrane pressure at $25^{\circ} \mathrm{C}$.

The permeation flux was obtained by using the equation:

$$
J=\frac{V}{A \times \Delta t}
$$

where $J\left(\mathrm{~L} \mathrm{~m}^{-2} \mathrm{~h}^{-1}\right)$ and $V(\mathrm{~L})$ were the pure water flux and volume of permeation over certain operation time $\Delta t(\mathrm{~h})$, respectively, and $A\left(\mathrm{~m}^{2}\right)$ was the effective membrane area.

The salt rejection was calculated by the following equation:

$$
R \%=\left(1-\frac{C_{\mathrm{P}}}{C_{\mathrm{f}}}\right) \times 100 \%
$$

where $C_{\mathrm{P}}\left(\mathrm{g} \mathrm{L}^{-1}\right)$ and $C_{\mathrm{f}}\left(\mathrm{g} \mathrm{L}^{-1}\right)$ were the salt concentrations in permeate and feed respectively. Salt concentration was determined by measuring the conductivity of the salt solution with a conductance meter (DDS-307, Shanghai INESA \& Scientific Instrument Co. Ltd, China). All tests were performed at least three times.

Membranes were filtrated in pure water under the linear regression over a range of feed pressure, then the intrinsic membrane resistance $\left(R_{\mathrm{m}}\right)$ was calculated and obtained by the following formula: ${ }^{26}$

$$
F=P /\left(\mu R_{\mathrm{m}}\right)
$$

where, $F$ was the pure water flux, which was related to the feed pressure, $P$. And $\mu$ referred to the dynamic viscosity of water. The $R_{\mathrm{m}}$ was used to estimate the structural property of PA selective layer. ${ }^{34}$

\subsection{Anti-fouling performance evaluation}

The anti-fouling properties of RO membranes were evaluated by filtration tests in $\mathrm{NaCl}$ solution with certain foulants. BSA (1000 ppm, $\mathrm{pH}=7.0$ ) and DTBA (50 ppm, $\mathrm{pH}=7.0$ ) were respectively dissolved in $2000 \mathrm{ppm} \mathrm{NaCl}$ solution as fouling feed solutions to simulate proteins and positively charged surfactant in desalination. The process of filtration test was as follow: (1) a stable pure water flux $\left(J_{\mathrm{o}}\right)$ was obtained after that membrane was filtrated in pure water for $1 \mathrm{~h}\left(1.6 \mathrm{MPa}, 25^{\circ} \mathrm{C}\right)$; (2) pure water was replaced by the fouling feed solution for $10 \mathrm{~h}$ to measure the flux $\left(J_{t}\right)$ under the fouling conditions (1.6 MPa, $\left.25{ }^{\circ} \mathrm{C}\right) ;(3)$ membranes were rinsed by pure water for $1 \mathrm{~h}\left(0 \mathrm{MPa}, 25^{\circ} \mathrm{C}\right)$. (4) The recovery flux $\left(J_{\mathrm{r}}\right)$ for $1 \mathrm{~h}$ was tested with pure water in the cell system (1.6 MPa, $\left.25{ }^{\circ} \mathrm{C}\right)$.

Indeed, flux recovery ratio (FRR) and total flux decline ratio $\left(D R_{t}\right)$ were two essential parameters to estimate the anti-fouling properties of RO membranes. ${ }^{44,45}$

The FRR and $\mathrm{DR}_{\mathrm{t}}$ were calculated by the following equations:

$$
\begin{gathered}
\mathrm{FRR}=\frac{J_{\mathrm{r}}}{J_{0}} \times 100 \% \\
\mathrm{DR}_{\mathrm{t}}=\left(1-\frac{J_{t}}{J_{\mathrm{o}}}\right) \times 100 \%
\end{gathered}
$$

where $J_{\mathrm{o}}$ was the initial water flux, $J_{t}$ was the water flux measured after $10 \mathrm{~h}$ in the model fouling solution, and $J_{\mathrm{r}}$ was the recovery water flux after washing.

\section{Results and discussion}

\subsection{Diffusion behavior of MPD monomers}

The diffusion behavior of MPD from the aqueous phase to the organic phase has an essential role in the thickness of the PA selective layer. The absorbance variation of MPD at $289 \mathrm{~nm}$ in $n$ hexane versus diffusion time is shown in Fig. 1(b). The absorbance of MPD becomes weak when Arg is added in the aqueous solution, indicating lower concentration of MPD in hexane. This result implies that the diffusion rate of MPD from the aqueous phase to the organic phase can be decelerated by Arg. Also, the higher of the Arg concentration in the aqueous solution, the lower the MPD monomers diffusion rate into the organic phase. The reason why Arg reduces the diffusion rate of MPD is that the hydrophilic ion pairs formed between Arg and MPD molecules in the aqueous solution, and these ion pairs can slowly cross the liquid-organic interface due to their hydrophilic nature. Hence, the introduction of Arg lessens MPD to transfer into the organic solution, causing a thinner reaction zone for interfacial polymerization to be likely to form thinner PA selective. Moreover, the thickness of the PA selective layer could be estimated by SEM method (see Section 3.4).

\section{2. $\mathrm{pH}$ value of the aqueous phase solution}

In order to further investigate the final performance of $\mathrm{RO}$ membranes, the effect of the $\mathrm{pH}$ value of the aqueous solution on the formation of the PA selective layer was studied. It can be seen from Table 1 that the pure Arg aqueous solution shows alkaline so that the $\mathrm{pH}$ values of the MPD and Arg mixture aqueous solution is increased. It is accepted that the hydrogen chloride is the byproduct during the interfacial polymerization, and the removal of hydrogen chloride facilitates the positive reaction of the chemical equilibrium. ${ }^{46,47}$ The Arg in the 

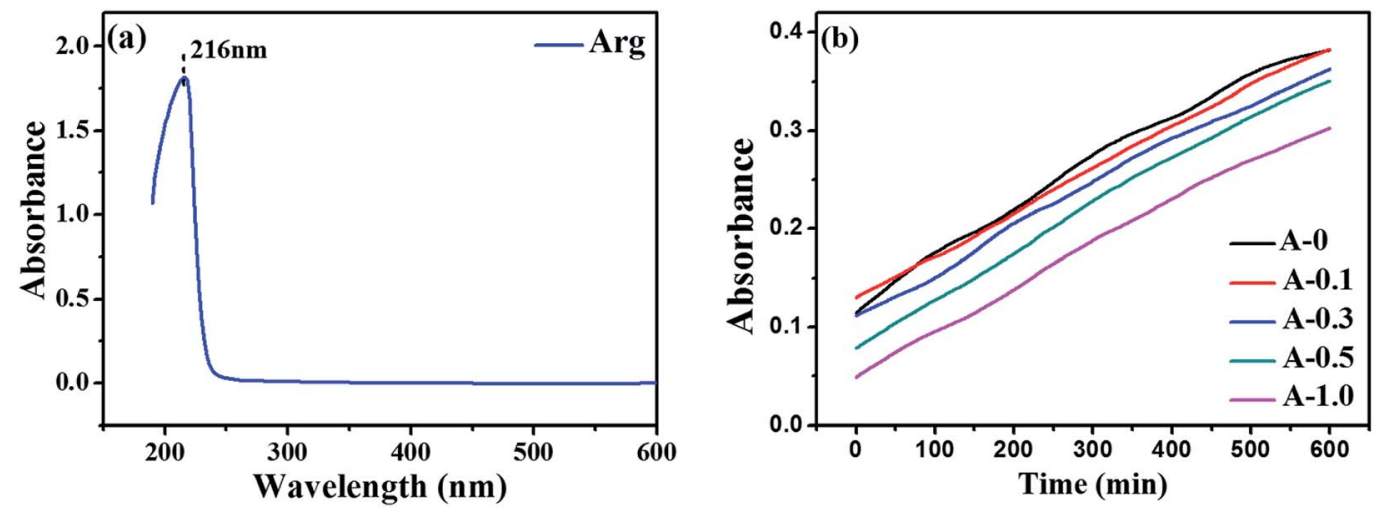

Fig. 1 UV-vis spectroscopy analysis: (a) the absorbance of Arg; (b) the absorbance variation of MPD in hexane at $289 \mathrm{~nm}$ versus diffusion time.

aqueous phase solution may accelerate the polymerization reaction via neutralizing the acid produced during amide formation, thus forming a relatively dense skin layer on the membrane surface to show a high salt rejection. ${ }^{48}$ However, when the $\mathrm{pH}$ of the aqueous phase solution is too high, the hydrolysis of acid chloride groups in TMC will result in the formation of less crossing-linking and looser top skin layer, thereby the salt rejection of the RO membrane could decrease $^{46,49}$ Therefore, the proper addition of Arg may be in favor of promoting the reaction proceed to optimize the performance of RO membranes. The role of the $\mathrm{pH}$ value of the aqueous solution in the separation performance of the resulting RO membrane will be discussed later.

\subsection{Chemical structure of the polyamide TFC membranes}

ATR-FTIR was used to analyze the chemical structure of RO membranes, and the results are shown in Fig. 2. Pure Arg and MPD were separately reacted with TMC on the PSF support layer through interfacial polymerization, and their ATR-FTIR results are shown in Fig. 2(a). The amide groups at $1662 \mathrm{~cm}^{-1}$ are ascribed to the reaction between the amine groups of Arg or MPD and the acyl chloride groups of TMC, indicating Arg could be introduced into the PA selective layer through interfacial polymerization. From Fig. 2(b), the amide groups at $1662 \mathrm{~cm}^{-1}$ prove that the PA selective layers are successfully formed via interfacial polymerization. Furthermore, the evident peaks at 1584,1486 and $1237 \mathrm{~cm}^{-1}$ are due to the stretching vibration of the $\mathrm{C}=\mathrm{C}$ bonds of the aromatic ring, the $\mathrm{C}-\mathrm{C}$ bond and the aromatic ether bond of the PSF support layer. ${ }^{50}$ However, the characteristic peaks $\mathrm{C}=\mathrm{N}$ bonds $\left(1640-1690 \mathrm{~cm}^{-1}\right)$ of Arg are not observed, which may be overlapped by the strong peaks of the PSF support layer and PA selective layer. ${ }^{51}$

Hence, XPS was adopted to analyze the surface composition of the PA selective layers, and the XPS spectra are illustrated in Fig. 3. The main peaks located at $285.0,400.0$ and $532.0 \mathrm{eV}$ refer to carbon $(\mathrm{C})$, nitrogen $(\mathrm{N})$ and oxygen $(\mathrm{O})$ elements, respectively. ${ }^{52}$ The relative surface atomic concentrations of all samples are listed in Table 2. The data shows that both the content of nitrogen atom $(\mathrm{N})$ and the atomic ratio of nitrogenoxygen (N/O) in the modified RO membranes are higher than those in the unmodified membranes because of the multiple amine groups in Arg. Hence, the result declares that Arg has been successfully introduced into the PA selective layer. Also, the N/O ratio decreases when the addition of Arg reaches $1.0 \mathrm{wt} \%$, which may occur because too high $\mathrm{pH}$ value of the aqueous solution causes the hydrolysis of acid chloride group as discussed in Section 3.2.
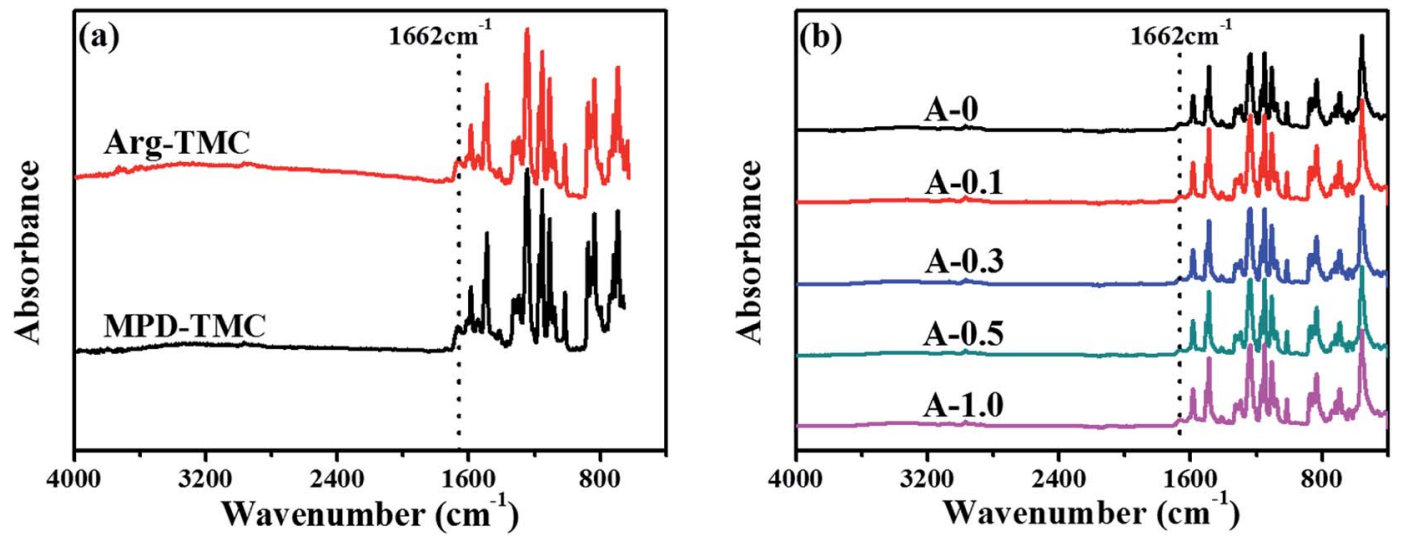

Fig. 2 ATR-FTIR spectra of the polyamide TFC membranes: (a) Arg and MPD separately react with TMC onto the PSF support layer; (b) the resulting polyamide TFC membranes. 


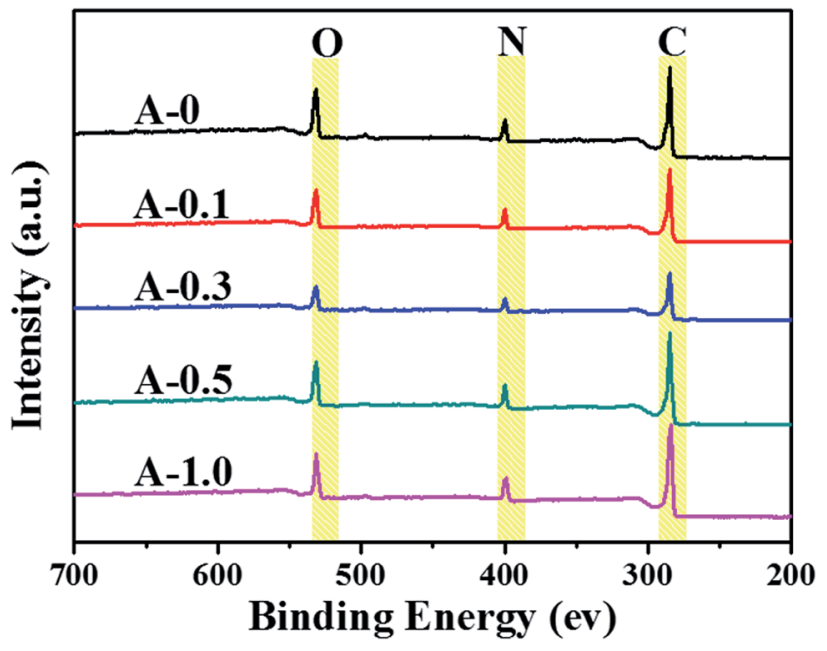

Fig. 3 Wide-scan of XPS for the polyamide TFC membranes.

\subsection{Morphologies of the polyamide TFC membranes}

The surface and the cross-section morphologies and surface roughness of the RO membrane were measured by SEM and AFM measurements. According to Fig. 4(a), the surface morphology of all samples shows typical ridge-valley structure due to the interfacial polymerization..$^{53}$ The result shows that the addition of Arg has no significant effect on the surface morphology of the RO membrane.

Furthermore, it can be seen from Table 3 that the value of $R_{\mathrm{p}-}$ v,$R_{\text {avg }}$ and $R_{\mathrm{ms}}$ decreases with the content of Arg increases. In detail, the $R_{\mathrm{ms}}$ of A-0 is $41.3 \pm 2.4 \mathrm{~nm}$ while the $R_{\mathrm{ms}}$ of A-0.1, A$0.3, \mathrm{~A}-0.5$ and Arg-1.0 are $35.8 \pm 1.7,33.5 \pm 2.1,31.8 \pm 1.5$ and $28.6 \pm 2.0 \mathrm{~nm}$, respectively, suggesting the surface roughness of RO membranes becomes smoother after the incorporation of Arg. It is widely acknowledged that the surface roughness is affected by the types and concentration of aqueous and organic monomers. And when an aliphatic monomer takes part in interfacial polymerization, the less roughness of the membrane surface may be obtained. ${ }^{12,54}$

The thickness of the PA selective layer was measured according to the representative cross-section image tested by SEM. The interface between the PA skin layer and the PSF support layer was marked by a red bar, as shown in Fig. 4(c). And the skin layer thickness of each membrane was listed in Table 3. The average thickness of A-0 is $277.6 \mathrm{~nm}$ whereas the average thickness of the PA selective layer of A-0.1, A-0.3, A-0.5 and $\mathrm{A}-1.0$ are 263.4, 249.6, 235.3 and $220.2 \mathrm{~nm}$, respectively.

Table 2 Relative surface atomic concentrations of the polyamide TFC membranes

\begin{tabular}{lllll}
\hline Sample & C (\%) & N (\%) & O (\%) & N/O \\
\hline A-0 & 79.28 & 8.13 & 12.59 & 0.64 \\
A-0.1 & 79.48 & 9.25 & 11.27 & 0.82 \\
A-0.3 & 79.31 & 9.40 & 11.28 & 0.83 \\
A-0.5 & 80.03 & 9.08 & 10.89 & 0.84 \\
A-1.0 & 79.50 & 9.03 & 11.47 & 0.79
\end{tabular}

This result indicates that the thickness of the PA selective layer gradually decreases with the dosage of Arg increases, which is ascribed to the lower MPD monomer concentration in the reaction zone under the influence of Arg as discussed in Section 3.1. The decreased thickness of the PA selective layer is beneficial to improve the water flux by reducing the hydraulic resistance to water permeation.

\subsection{Surface properties of the polyamide TFC membranes}

The hydrophilicity of the membrane surface vitally influences the permeability and anti-fouling property, which was estimated by contact angle measurement and the results are shown in Fig. 5. The contact angle of A- 0 is $76.9^{\circ}$, whereas the contact angle of A-0.1, A-0.3, A-0.5 and A-1.0 are $49.9^{\circ}, 51.9^{\circ}, 51.3^{\circ}$ and $51.0^{\circ}$, respectively, indicating that the addition of Arg enhances the hydrophilicity of the membrane surface. Generally, the water contact angle of a solid surface is governed by both the chemical composition and the surface roughness. ${ }^{55}$ On the one hand, when Arg was incorporated into the polyamide selective layer, the existence of carboxyl groups of Arg suggests more hydrogen bond interaction between water molecules and membrane surface, resulting in the low contact angle. On the other hand, the PA selective layer becomes smoother with the increasing dosage of Arg, and the smoother hydrophilic surface may result in a declined contact angle on the theory of the Wenzel model..$^{56}$ Hence, by combining these two factors, the contact angle of the modified membrane surface has no significant change with the different content of Arg but is still lower than the unmodified membranes.

Surface charge of membranes was measured in the $\mathrm{pH}$ range of 3.0-10.0, and the results are shown in Fig. 6. As the $\mathrm{pH}$ value of the test solution increases, the negative charges of all samples are improved. The addition of Arg causes PA selective layer with less negative charge, and its negative charges are gradually decreased with the content of Arg increases. The phenomenon shows that the surface charge of the modified membranes can be adjusted by the limit of Arg content. The reduced negative charge of the membrane surface is attributed by the multiple amine groups in one Arg molecule, which is beneficial to mitigate the absorption of positively charged foulants on the membrane surface due to the electrostatic repulsion.

\subsection{Separation performance}

The pure water flux and salt rejection are two essential parameters to measure the separation performance of the RO membrane. As shown in Fig. 7, the introduction of Arg is beneficial to increase the water flux and salt rejection of the RO membrane. Specifically, the water flux and salt rejection increase from $46.46 \mathrm{~L} \mathrm{~m}^{-2} \mathrm{~h}^{-1}$ and $96.34 \%$ to $54.13 \mathrm{~L} \mathrm{~m}^{-2} \mathrm{~h}^{-1}$ and $98.36 \%$ for membranes with an Arg content of $0.5 \mathrm{wt} \%$.

There are three possible reasons explaining why Arg could enhance the permeation performance of RO membranes. Firstly, the thickness of the PA selective layer is reduced due to the slower monomer diffusion rate into the organic phase. Secondly, introducing aliphatic Arg into the rigid structure of 

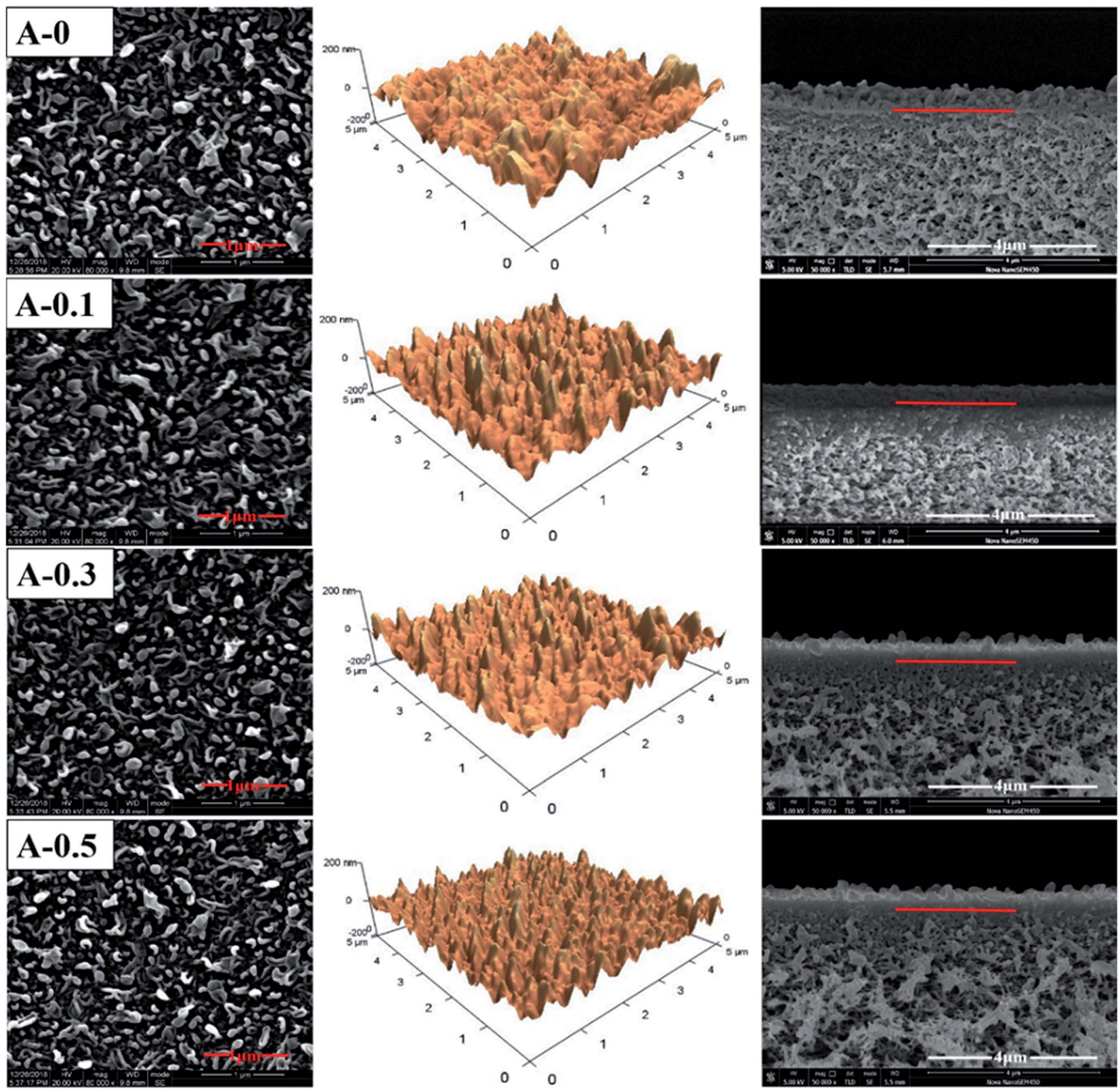

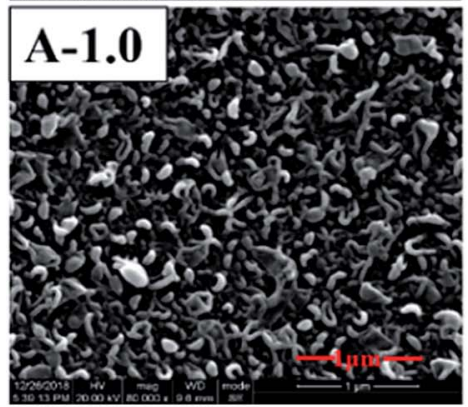

(a)

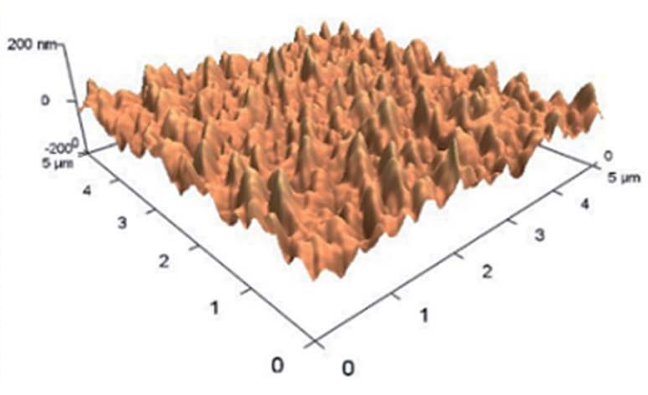

(b)

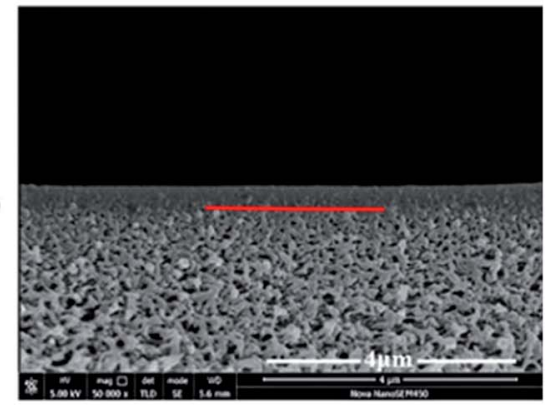

(c)

Fig. 4 Morphologies of the polyamide TFC membranes: (a) top surface SEM images; (b) AFM images; (c) cross-section SEM images.

the PA selective layer could increase the flexibility of the molecule chain and therefore makes the modified membranes to be more swellable. Thirdly, the formation of the hydration layer near the membranes surface can improve the driving force of water molecules to pass through the membranes. ${ }^{57}$ The more hydrophilic surface of the modified membraned is conductive to form hydration layer with water molecule via hydrogen bonding. ${ }^{58}$ Also, the guanidine group of Arg exists as 
Table 3 The detail values of the surface roughness and average thickness of the polyamide selective layers

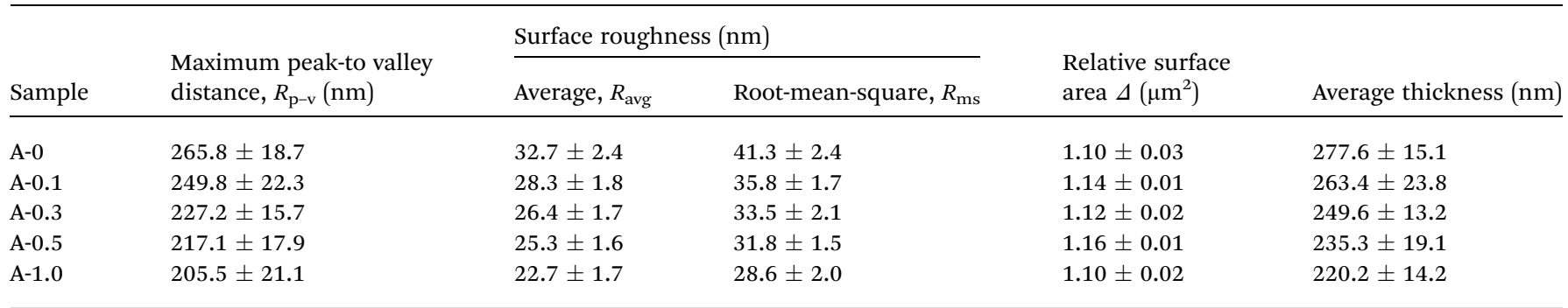

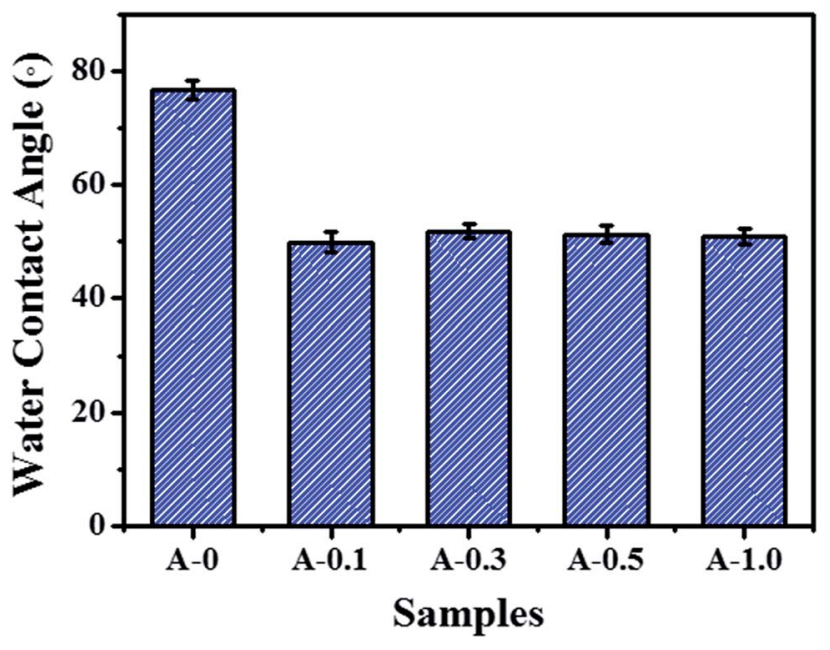

Fig. 5 The contact angle of the polyamide TFC membranes with different content of Arg.

guanidinium cation $\left(\mathrm{Gdm}^{+}\right)$in aqueous solution. $\mathrm{Gdm}^{+}$could pair with each other to form stable $\mathrm{Gdm}^{+}-\mathrm{Gdm}^{+}$pairs in water, which can bind with ample water molecules to form a stable cluster with water molecules, that is, the stable hydration layer near the membranes could be constructed. ${ }^{59,60}$ These factors above could facilitate the transport of water molecules through

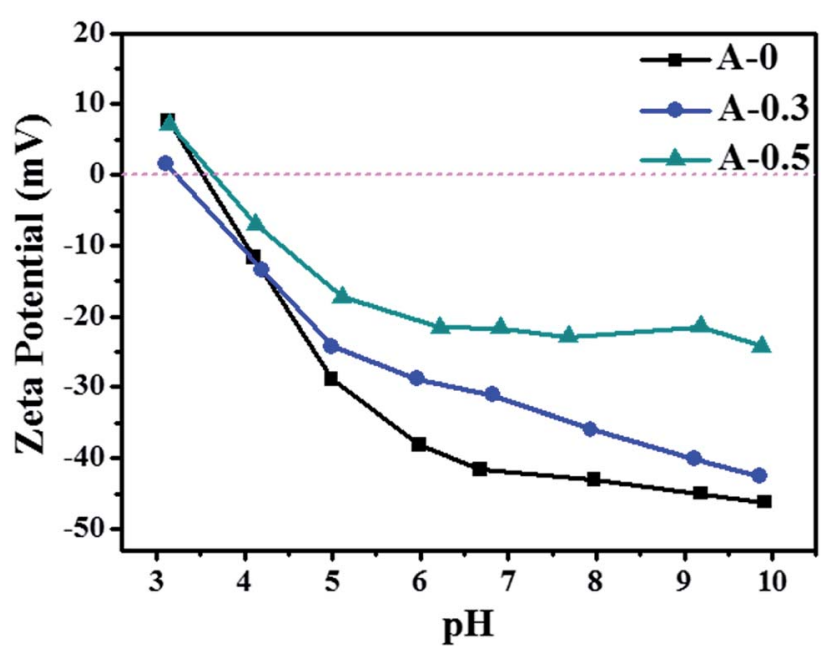

Fig. 6 Zeta potentials of the polyamide TFC membranes at different $\mathrm{pH}$ values. membranes by reducing the hydraulic resistance to water permeation, resulting in the improvement of the water flux. ${ }^{61,62}$

As for the salt rejection of the RO membrane, which presents a trend of increase-decrease with the content of Arg increases. When the dosage of Arg is $0.5 \mathrm{wt} \%$, more Arg molecules participate in interfacial polymerization and the addition of Arg probably promotes the reaction proceed as described in Section 3.2, which make PA active layer relatively denser and thereby maintaining highest salt rejection. However, when the dosage of Arg reaches $1.0 \mathrm{wt} \%$, the $\mathrm{pH}$ value of the aqueous phase is more than 11 as shown in Table 1 and more hydrophilic ion pairs are formed between MPD molecules and more Arg. The two factors may disturb the formation of crossing-linking skin layer, thereby resulting in the decline in the salt rejection. Although the highest addition of Arg influences the formation of the PA network, there is no unfavorable defect in the PA selective layer, hence the salt rejection still keeps a high level.

Furthermore, the salt rejection of the modified membranes is higher than the unmodified membranes. On the one hand, the reaction between Arg and TMC could form another crosslinked structure and the stable $\mathrm{Gdm}^{+}-\mathrm{Gdm}^{+}$pairs in the PA selective layer may be produced in water, which probably makes the structure of the PA selective more integrated. On the other hand, the formation of stable hydration layer near the membrane surface could alleviate the effect of concentration polarization by reducing the concentration of salt ions near the membranes, thus reducing the flux of salt ions. These behaviors described above possibly impede the passage of salt ions to enhance the salt rejection.

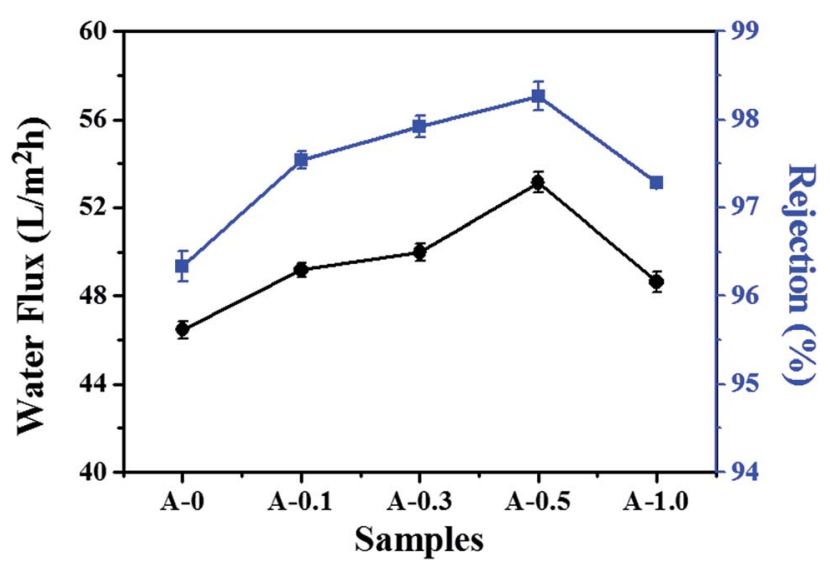

Fig. 7 The separation performance of the polyamide TFC membranes tested with $2000 \mathrm{ppm} \mathrm{NaCl}$ aqueous solution at $1.6 \mathrm{MPa}$ and $25^{\circ} \mathrm{C}$. 

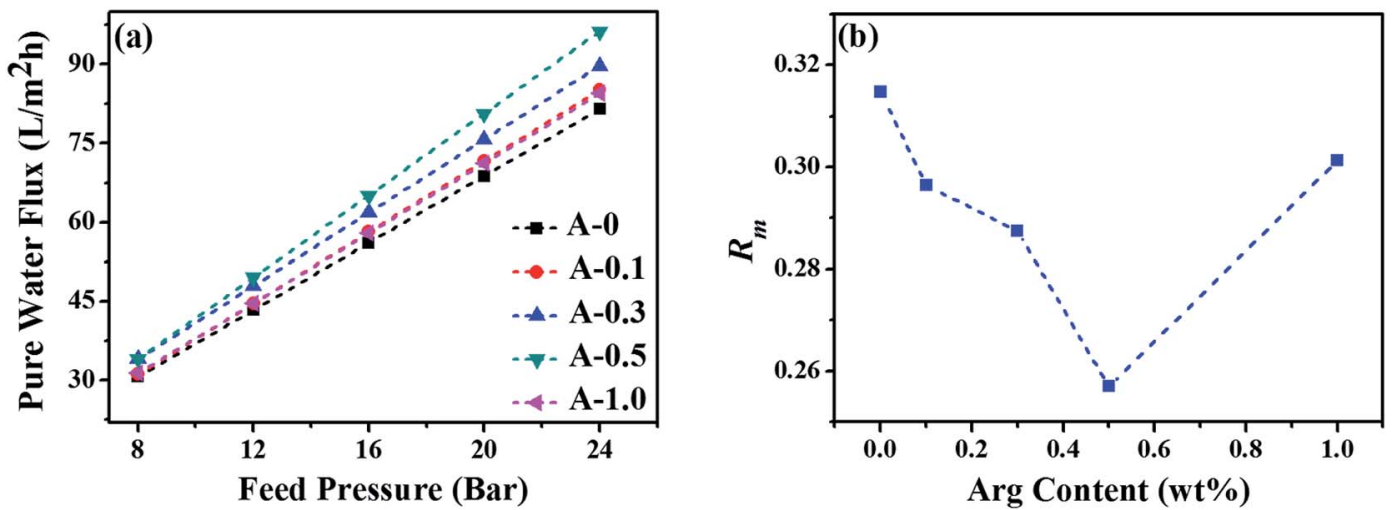

Fig. 8 (a) The pure water flux of the polyamide TFC membranes under the different feed pressure and (b) the intrinsic membrane resistance $\left(R_{\mathrm{m}}\right)$ of the polyamide TFC membranes.

The pure water flux and salt rejection of RO membranes could preliminarily reflect the internal network structure of the PA selective layer. ${ }^{63}$ The above results show that when the dosage of Arg is $0.5 \mathrm{wt} \%$, the structure of the $\mathrm{RO}$ membrane is optimal at around this point. Additionally, $R_{\mathrm{m}}$ is another
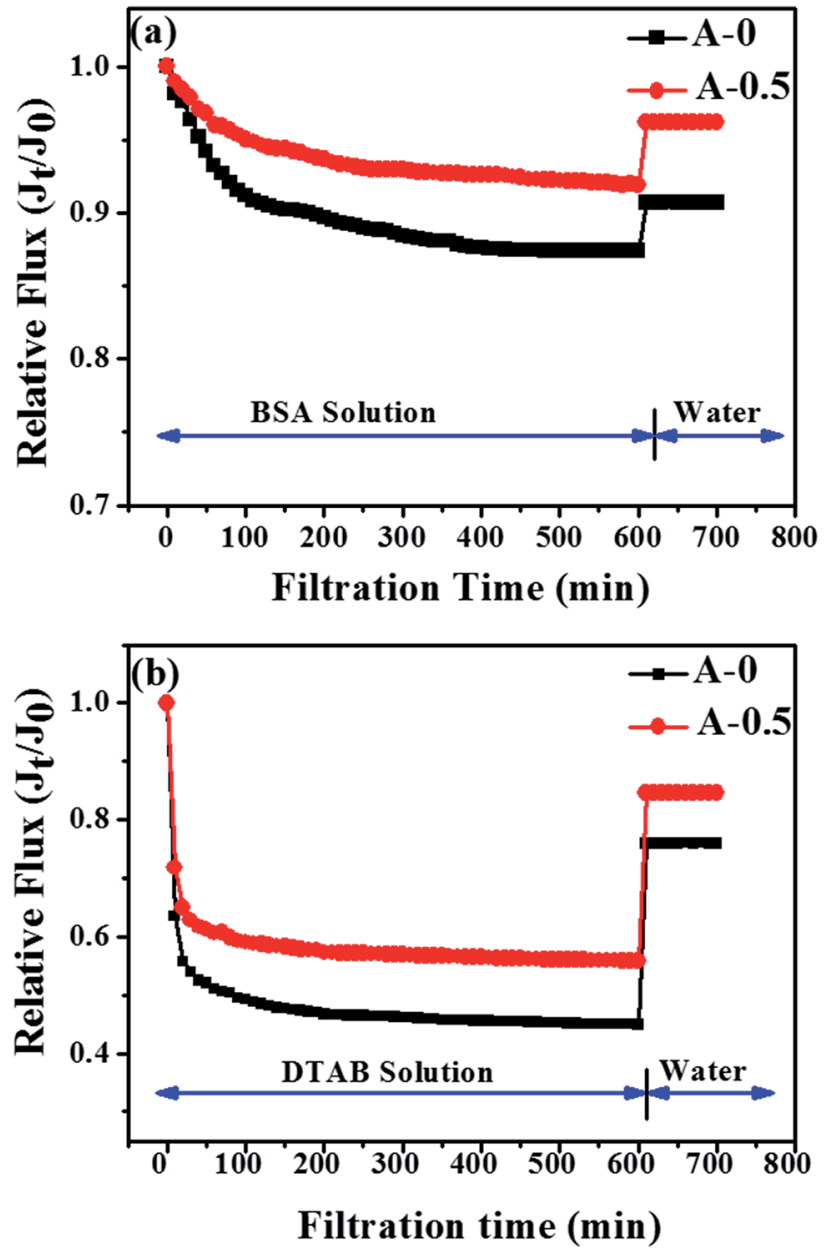

Fig. 9 Time-dependent relative water flux of A-0 and A-0.5 tested with (a) $2000 \mathrm{ppm} \mathrm{NaCl}$ and $1000 \mathrm{ppm}$ BSA aqueous solution; (b) $2000 \mathrm{ppm} \mathrm{NaCl}$ and $50 \mathrm{ppm}$ DTBA aqueous solution at $25^{\circ} \mathrm{C}$ and 1.6 $\mathrm{MPa}$. parameter to comprehend the structural properties of the RO membrane, and the results are shown in Fig. $8(\mathrm{~b}) . R_{\mathrm{m}}$ is calculated by the reciprocal of the slope of the curves in Fig. 8(a). The lowest value of $R_{\mathrm{m}}$ is obtained when the content of Arg is $0.5 \mathrm{wt} \%$, indicating the balance between the cross-linking densities, the active surface area and the thickness of the PA selective layer would be best at this point. That is to say, $0.5 \mathrm{wt} \%$ addition of Arg in the aqueous phase solution is the most appropriate. Altogether, Arg played a significant role in enhancing the separation performance of RO membranes.

\subsection{Fouling resistance performance}

Fouling resistance of the RO membrane was evaluated by filtering with BSA and DTAB solution. BSA and DTAB are used to stimulate the protein and positively charged surfactant under the fouling situation. The experimental results are presented in Fig. 9, and the exact values of flux recovery ratio (FRR) and total flux decline ratio $\left(\mathrm{DR}_{\mathrm{t}}\right)$ are shown in Table 4 . In general, a lower value of $\mathrm{DR}_{\mathrm{t}}$ and a higher value of FRR reflect the better antifouling properties of the RO membrane.

When BSA was chosen as model foulant, the $\mathrm{DR}_{\mathrm{t}}$ and FRR of A- 0 are $12.6 \%$ and $90.7 \%$ whereas the $\mathrm{DR}_{t}$ and FRR of A-0.5 are $8.1 \%$ and $96.2 \%$, respectively. The results show that the antifouling property of the modified RO membrane is enhanced. The formation of the effective hydration layer near the modified membranes can resist the deposition and adsorption of protein onto the membrane surface. Furthermore, the smoother surface also lessens the adsorption of protein on the membrane surface due to the reduction of adhesion sites.

When tested in DTAB solution, the relative water flux of A0 and A-0.5 both decline fast because of the strong electrostatic attraction between the positively charged DTAB molecules

Table 4 The values of FRR and $\mathrm{DR}_{t}$ of $A-0$ and $A-0.5$ during filtrating BSA and DTBA solution

\begin{tabular}{llllll}
\hline & \multicolumn{2}{c}{ BSA solution } & & & \multicolumn{2}{c}{ DTAB solution } \\
\cline { 2 - 3 } & A-0 & & A-0 & A-0.5 \\
\hline DR $_{\mathrm{t}}$ & $12.6 \%$ & $8.1 \%$ & & $55.1 \%$ & $44.1 \%$ \\
FRR & $90.7 \%$ & $96.2 \%$ & & $75.9 \%$ & $84.6 \%$
\end{tabular}




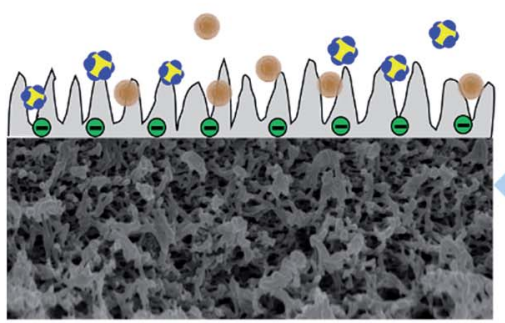

MPD-TMC RO Membrane

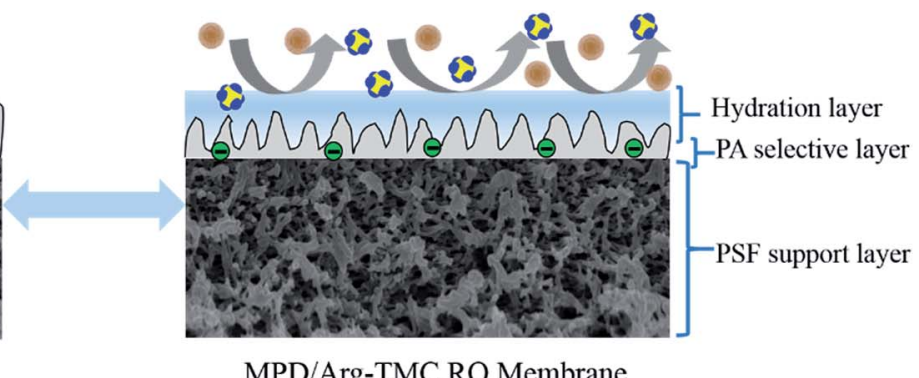

: Negative charge

MPD/Arg-TMC RO Membrane

28 : Surfactant

Scheme 2 The illustration of the anti-fouling properties of the polyamide TFC membranes.

and the negatively charged membrane surface. However, A-0.5 shows a higher FRR and lower $\mathrm{DR}_{\mathrm{t}}$, indicating that the addition of Arg is in favor of alleviating membranes fouling. The declined negative charge on the modified membrane surface as described in zeta potential test can weaken the electrostatic attraction between the membrane surface and DTAB molecules, thereby enhancing the anti-fouling property of RO membranes.

Altogether, the RO membrane containing Arg has better resistance to protein and positively charged foulants due to higher hydrophilic, smoother and less negatively charged membrane surface. The possible illustration of the anti-fouling properties is presented in Scheme 2.

\section{Conclusion}

In this study, we adopted a facile and effective method to simultaneously improve the separation performance and antifouling properties of RO membranes. L-arginine (Arg) was chosen as an additive in the aqueous phase to take part in interfacial polymerization, thereby regulating the chemical structure and surface properties of the polyamide selective layer. The introduction of Arg made the polyamide selective layer thinner, smoother, higher hydrophilic and less negatively charged. As a result, for the optimized polyamide TFC membrane, its water flux increased from the original $46.46 \mathrm{~L}$ $\mathrm{m}^{-2} \mathrm{~h}^{-1}$ to $54.13 \mathrm{~L} \mathrm{~m}^{-2} \mathrm{~h}^{-1}$ while its salt rejection improved from the original $96.34 \%$ to $98.36 \%$. Using BSA and DTAB as model foulants, a better pure water flux recovery ratio of the modified RO membrane was obtained after the entire fouling and cleaning tests. The experimental results indicated that the resulting membranes exhibited better resistance to protein and positively charged foulants. To summarize, the optimized modified membrane showed enhanced separation performance and anti-fouling properties.

\section{Conflicts of interest}

There are no conflicts of interest to declare.

\section{Acknowledgements}

This work was support by the National Natural Science Foundation of China (NSFC, Grant No. 51503134, 51702282) and
State Key Laboratory of Polymer Materials Engineering (Grant No. SKLPME 2017-3-02). The authors would like to thank Lingzhu Yu (National Engineering Research Center for Biomaterials, Sichuan University) for help in characterizing AFM.

\section{References}

1 M. A. Shannon, P. W. Bohn, M. Elimelech, J. G. Georgiadis, B. J. Mariñas and A. M. Mayes, Science and technology for water purification in the coming decades, Nature, 2008, 452(7185), 301-310.

$2 \mathrm{M}$. Elimelech and W. A. Phillip, The future of seawater desalination: energy, technology, and the environment, Science, 2011, 333(6043), 712-717.

3 T. Uemura and M. Henmi, Thin-Film Composite Membranes for Reverse Osmosis, Advanced membrane technology and applications, 2008, pp. 1-19.

$4 \mathrm{H}$. Strathmann and W. Richard, Baker Membrane Technology and Applications, 2nd ed., 2004, John Wiley \& Sons, Ltd., UK, J. Membr. Sci., 2005, 246(1), 113-114.

$5 \mathrm{~N}$. Ghaffour, J. Bundschuh, H. Mahmoudi and M. F. A. Goosen, Renewable energy-driven desalination technologies: a comprehensive review on challenges and potential applications of integrated systems, Desalination, 2015, 356, 94-114.

6 E. M. V. Wagner, A. C. Sagle, M. M. Sharma and B. D. Freeman, Effect of crossflow testing conditions, including feed $\mathrm{pH}$ and continuous feed filtration, on commercial reverse osmosis membrane performance, $J$. Membr. Sci., 2009, 345(1), 97-109.

$7 \mathrm{D}$. Li and H. Wang, Recent developments in reverse osmosis desalination membranes, J. Mater. Chem., 2010, 20(22), 4551-4566.

8 K. P. Lee, T. C. Arnot and D. Mattia, A review of reverse osmosis membrane materials for desalinationdevelopment to date and future potential, J. Membr. Sci., 2011, 370(1), 1-22.

9 J. E. Cadott, R. J. Petersen, R. E. Larson and E. E. Erickson, A new thin-film composite seawater reverse osmosis membrane, Desalination, 1980, 32(1-3), 25-31.

10 T. Matsuura, Progress in membrane science and technology for seawater desalination - a review, Desalination, 2001, 134(1), 47-54. 
11 S. Y. Kwak, M. O. Yeom, I. J. Roh, Y. K. Dong and J. J. Kim, Correlations of chemical structure, atomic force microscopy (AFM) morphology, and reverse osmosis (RO) characteristics in aromatic polyester high-flux RO membranes, J. Membr. Sci., 1997, 132(2), 183-191.

12 Y. J. Song, P. Sun, L. L. Henry and B. H. Sun, Mechanisms of structure and performance controlled thin film composite membrane formation via interfacial polymerization process, J. Membr. Sci., 2005, 251(1), 67-79.

13 M. Asadollahi, D. Bastani and S. A. Musavi, Enhancement of surface properties and performance of reverse osmosis membranes after surface modification: a review, Desalination, 2017, 420, 330-383.

14 A. R. Bartman, E. Lyster, R. Rallo, P. D. Christofides and Y. Cohen, Mineral scale monitoring for reverse osmosis desalination via real-time membrane surface image analysis, Desalination, 2011, 273(1), 64-71.

15 S. R. Pandey, V. Jegatheesan, K. Baskaran and L. Shu, Fouling in reverse osmosis (RO) membrane in water recovery from secondary effluent: a review, Rev. Environ. Sci. Bio/Technol., 2012, 11(2), 125-145.

16 Y. Hu, C. Gao, Y. Fang, K. Lu, P. Yu, S. Yu, S. Li and Y. Shi, Enhancing the performance of aromatic polyamide reverse osmosis membrane by surface modification via covalent attachment of polyvinyl alcohol (PVA), J. Membr. Sci., 2016, 501, 209-219.

17 D. Zhao and S. Yu, A review of recent advance in fouling mitigation of $\mathrm{NF} / \mathrm{RO}$ membranes in water treatment: pretreatment, membrane modification, and chemical cleaning, Desalin. Water Treat., 2015, 55(4), 870-891.

18 D. Rana and T. Matsuura, Surface modifications for antifouling membranes, Chem. Rev., 2010, 110(4), 24482471.

19 Y. Mo, A. Tiraferri, N. Y. Yip, A. Adout, X. Huang and M. Elimelech, Improved antifouling properties of polyamide nanofiltration membranes by reducing the density of surface carboxyl groups, Environ. Sci. Technol., 2012, 46(24), 13253-13261.

20 L. Zheng, H. S. Sundaram, Z. Wei, C. Li and Z. Yuan, Applications of zwitterionic polymers, React. Funct. Polym., 2017, 118, 51-61.

21 S. H. Park, Y. S. Ko, S. J. Park, J. S. Lee, J. Cho, K. Y. Baek, I. T. Kim, K. Woo and J. H. Lee, Immobilization of silver nanoparticle-decorated silica particles on polyamide thin film composite membranes for antibacterial properties, $J$. Membr. Sci., 2016, 499, 80-91.

22 G. Kang, L. Ming, B. Lin, Y. Cao and Y. Quan, A novel method of surface modification on thin-film composite reverse osmosis membrane by grafting poly(ethylene glycol), Polymer, 2007, 48(5), 1165-1170.

23 F. Perreault, M. E. Tousley and M. Elimelech, Thin-Film Composite Polyamide Membranes Functionalized with Biocidal Graphene Oxide Nanosheets, Environ. Sci. Technol. Lett., 2016, 1(1), 71-76.

24 T. Zhang, K. Zhang, J. Li and X. Yue, Simultaneously enhancing hydrophilicity, chlorine resistance and antibiofouling of APA-TFC membrane surface by densely grafting quaternary ammonium cations and salicylaldimines, J. Membr. Sci., 2017, 528, 296-302.

25 L. Zhao and W. S. W. Ho, Novel reverse osmosis membranes incorporated with a hydrophilic additive for seawater desalination, J. Membr. Sci., 2014, 455(4), 44-54.

26 N. B. Barona Garry, L. Joohwan and J. Bumsuk, High performance thin film composite polyamide reverse osmosis membrane prepared via m-phenylenediamine and 2,2'-benzidinedisulfonic acid, Desalination, 2012, 291, 69-77.

27 L. I. Yafei, S. U. Yanlei, Y. Dong, X. Zhao, Z. Jiang, R. Zhang and J. Zhao, Separation performance of thin-film composite nanofiltration membrane through interfacial polymerization using different amine monomers, Desalination, 2014, 333(1), 59-65.

28 Y. Zhang, Y. Su, W. Chen, J. Peng, Y. Dong, Z. Jiang and H. Liu, Appearance of poly(ethylene oxide) segments in the polyamide layer for antifouling nanofiltration membranes, J. Membr. Sci., 2011, 382(1-2), 300-307.

29 Y. U. Sanchuan, M. Liu, L. Ü. Zhenhua, Y. Zhou and C. Gao, Aromatic-cycloaliphatic polyamide thin-film composite membrane with improved chlorine resistance prepared from m-phenylenediamine-4-methyl and cyclohexane-1,3,5tricarbonyl chloride, J. Membr. Sci., 2009, 344(1), 155-164.

30 Z. Yong, S. Yu, M. Liu and C. Gao, Polyamide thin film composite membrane prepared from m-phenylenediamine and m-phenylenediamine-5-sulfonic acid, J. Membr. Sci., 2006, 270(1), 162-168.

31 J. E. Cadotte, Alkali resistant hyperfiltration membrane, US Pat., 4,895,661, 1990-1-23.

32 Q. An, L. Feng, Y. Ji and H. Chen, Influence of polyvinyl alcohol on the surface morphology, separation and antifouling performance of the composite polyamide nanofiltration membranes, J. Membr. Sci., 2011, 367(1), 158-165.

33 L. B. Wright, N. A. Merrill, M. R. Knecht and T. R. Walsh, Structure of arginine overlayers at the aqueous gold interface: Implications for nanoparticle assembly, ACS Appl. Mater. Interfaces, 2014, 6(13), 10524-10533.

34 D. H. N. Perera, Q. Song, H. Qiblawey and E. Sivaniah, Regulating the aqueous phase monomer balance for flux improvement in polyamide thin film composite membranes, J. Membr. Sci., 2015, 487, 74-82.

35 R. Xu, G. Xu, J. Wang, J. Chen, F. Yang, J. Kang and M. Xiang, Influence of l-lysine on the permeation and antifouling performance of polyamide thin film composite reverse osmosis membranes, RSC Adv., 2018, 8(44), 25236-25247.

36 K. Peng, D. Wei, W. Tu, J. Hu, C. Liu and J. Yang, Construction of Guanidinium-rich Polymers and Their Applications, Acta Chim. Sin., 2016, 74(9), 713-725.

37 M. Duan, W. Zhi, J. Xu, J. Wang and S. Wang, Influence of hexamethyl phosphoramide on polyamide composite reverse osmosis membrane performance, Sep. Purif. Technol., 2010, 75(2), 145-155.

38 J. Wang, R. Xu, Y. Feng, K. Jian, Y. Cao and X. Ming, Probing influences of support layer on the morphology of polyamide selective layer of thin film composite membrane, J. Membr. Sci., 2018, 556, 374-383. 
39 F. Viatcheslav, Kinetics of film formation by interfacial polycondensation, Langmuir, 2005, 21(5), 1884.

40 P. W. Morgan and S. L. Kwolek, Interfacial Polycondensation. II. Fundamentals of Polymer Formation at Liquid Interfaces, J. Polym. Sci., 1959, 40(137), 299-327.

$41 \mathrm{M}$. Hirose, H. Ito and Y. Kamiyama, Effect of skin layer surface structures on the flux behaviour of RO membranes, J. Membr. Sci., 1996, 121(2), 209-215.

42 A. K. Ghosh, B. H. Jeong, X. Huang and E. M. V. Hoek, Impacts of reaction and curing conditions on polyamide composite reverse osmosis membrane properties, $J$. Membr. Sci., 2008, 311(1), 34-45.

43 A. E. Childress and M. Elimelech, Effect of solution chemistry on the surface charge of polymeric reverse osmosis and nanofiltration membranes, J. Membr. Sci., 1996, 119(2), 253-268.

44 R. Zhang, Y. Liu, M. He, Y. Su, X. Zhao, M. Elimelech and Z. Jiang, Antifouling membranes for sustainable water purification: strategies and mechanisms, Chem. Soc. Rev., 2016, 45(21), 5888-5924.

45 Y. Li, Y. Su, X. Zhao, R. Zhang, J. Zhao, X. Fan and Z. Jiang, Surface fluorination of polyamide nanofiltration membrane for enhanced antifouling property, J. Membr. Sci., 2014, 455, 15-23.

46 N. Zydowicz, P. Chaumont and M. L. Sotoportas, Formation of aqueous core polyamide microcapsules obtained via interfacial polycondensation: optimization of the membrane formation through $\mathrm{pH}$ control, J. Membr. Sci., 2001, 189(1), 41-58.

47 R. J. Petersen, Composite reverse osmosis and nanofiltration membranes, J. Membr. Sci., 1993, 83(1), 81-150.

48 M. Liu, S. Yu, T. Jie and C. Gao, Preparation, structure characteristics and separation properties of thin-film composite polyamide-urethane seawater reverse osmosis membrane, J. Membr. Sci., 2008, 325(2), 947-956.

49 C. Klaysom, S. Hermans, A. Gahlaut, S. V. Craenenbroeck and I. F. J. Vankelecom, Polyamide/polyacrylonitrile (PA/ PAN) thin film composite osmosis membranes: film optimization, characterization and performance evaluation, J. Membr. Sci., 2013, 445(20), 25-33.

50 V. Freger, J. Gilron and S. Belfer, TFC polyamide membranes modified by grafting of hydrophilic polymers: an FT-IR/AFM/ TEM study, J. Membr. Sci., 2002, 209(1), 283-292.

51 H. L. Zhang, Y. B. Gao and J. Gai, GuanidiniumFunctionalized Nanofiltration Membranes Integrating Antifouling and Antimicrobial Effect, J. Mater. Chem. A, 2018, 6(6), 6442-6454.

52 S. M. Xue, Z. L. Xu, Y. J. Tang and C. H. Ji, Polypiperazineamide Nanofiltration Membrane Modified by Different
Functionalized Multiwalled Carbon Nanotubes (MWCNTs), ACS Appl. Mater. Interfaces, 1944, 8(29), 19135-19144.

53 S. Y. Kwak, S. G. Jung, Y. S. Yoon and D. W. Ihm, Details of surface features in aromatic polyamide reverse osmosis membranes characterized by scanning electron and atomic force microscopy, J. Polym. Sci., Part B: Polym. Phys., 2015, 37(13), 1429-1440.

54 Y. H. Huang, W. C. Chao, W. S. Hung, Q. F. An, K. S. Chang, S. H. Huang, K. L. Tung, K. R. Lee and J. Y. Lai, Investigation of fine-structure of polyamide thin-film composite membrane under swelling effect by positron annihilation lifetime spectroscopy and molecular dynamics simulation, J. Membr. Sci., 2012, 417-418(suppl. 417-418), 201-209.

55 J. Zhang, X. Lu, W. Huang and Y. Han, Reversible Superhydrophobicity to Superhydrophilicity Transition by Extending and Unloading an Elastic Polyamide Film, Macromol. Rapid Commun., 2010, 26(6), 477-480.

56 P. S. S. And and R. Lipowsky, Contact Angles on Heterogeneous Surfaces: A New Look at Cassie's and Wenzel's Laws, Langmuir, 1998, 14(23), 6772-6780.

57 Y.-F. Mi, F.-Y. Zhao, Y.-S. Guo, X.-D. Weng, C.-C. Ye and Q.-F. An, Constructing zwitterionic surface of nanofiltration membrane for high flux and antifouling performance, J. Membr. Sci., 2017, 541, 29-38.

58 R. Astrid, H. C. Mei, H. J. Van Der Busscher and N. Willem, Microbial adhesion to poly(ethylene oxide) brushes: influence of polymer chain length and temperature, Langmuir, 2004, 20(25), 10949-10955.

59 M. Vazdar, J. Vymětal, J. Heyda, J. Vondrášek and P. Jungwirth, Like-charge guanidinium pairing from molecular dynamics and ab initio calculations, J. Phys. Chem. A, 2011, 115(41), 11193.

60 Q. Shi, Y. Su, W. Chen, J. Peng, L. Nie, L. Zhang and Z. Jiang, Grafting short-chain amino acids onto membrane surfaces to resist protein fouling, J. Membr. Sci., 2011, 366(1), 398404.

61 E. P. Chan, Deswelling of ultrathin molecular layer-by-layer polyamide water desalination membranes, Soft Matter, 2014, 10(17), 2949-2954.

62 E. P. Chan and S. C. Lee, Thickness-dependent swelling of molecular layer-by-layer polyamide nanomembranes, $J$. Polym. Sci., Part B: Polym. Phys., 2017, 55(5), 412-417.

63 D. H. N. Perera, S. K. Nataraj, N. M. Thomson, A. Sepe, S. Hüttner, U. Steiner, H. Qiblawey and E. Sivaniah, Roomtemperature development of thin film composite reverse osmosis membranes from cellulose acetate with antibacterial properties, J. Membr. Sci., 2014, 453(453), 212-220. 